\title{
Energetics and Cultural History
}

\author{
A Chapter of Ostwald's Philosophy
}

\section{By Henry Hess}

INSTEAD of regaling or wearying you with a recital of my own views or work, I crave your indulgence in laying before you some matter taken from a recent work in German by that dean of our profession, Dr. Wilhelm Ostwald, "Die Forderung des Tages"-"The Demand Ostwald, "Die Forderung des Tages"- "The Demand
of the Day." It is true that Dr. Ostwald is more generally known as a chemist, creating and marking an epoch, and as an inspiring teacher, and that he would, therefore not generally be considered a dean of engineers, yet true engineering in its widest sense was a decidedly fundaprofoundly impressed me that I wished to gain your appreciation by bringing it before you was Ostwald' lecture on "Energetics and Cultural History." Were its author a writer aspiring to the older distinction of the classic culture, I should hesitate to thus crib, but engineers are broad-minded, and desire only to give the widest spread to their discoveries and teachings; let that be my apology.

Ostwald defines energetics as that scientific conception which considers the physical idea of energy as the one which, for the time being, presents the most exact gathering of physico-chemical facts and laws. $\mathrm{Dr}$. Grechen pointed out that energeties is tirst a theory of physical phenomena, and that a connection of its result and methods of thought with the problems of the higher mental life is not immediately apparent. Energy, as the term is to-day scientifically defined, has but a loose connection with the moral quality of the same name. To the engineer, energy is a physically measurable quantity, best known to us as mechanical work. As chemistry teaches that coal, graphite, and carbon all represent the same substance, carbon, insofar as each of these may be changed into the other, so doss physics teach that mechanical work may be changed into heat, light, electricity, chemical effects, etc. As impossible as it is to increase chemical effects, etc. As impossible as it is to increase
or decrease a given quantity of carbon by the most complicated transformations, so impossible is it to increas or decrease a given amount of work by the most intricat transformations. For both there rules the law of conservation. That which we can neither create nor destroy the charater of substances, as have also work and transformation products. These latter are given the common term "energv," while the science of the law governing the manifold transformation of energy is governing the

Prefacing that this is all well known, Ostwald answer the question for the reason of this repetition by the statement that these laws not only regulate, but even make possible, our very existence. Life is based on a continnal change of energy in our body; with the instant of interruption of this change death ensues. But not only individual life, but all social life also, is directly domiindividual life, but all social life also, is directly domi-
nated by the laws of energy. That a speaker may appear before you is due to the energy of some means of conbefore you is due to the energy of some means of con-
veyance; that you hear a speaker is due to the energy conveyed from his vocal cords to you in sound waves that you understand a speaker is based on the energy of your own mental activity. That is why we must, first of all, be practicers of energetics, long before we may choose any other view of the world-why nothing may happen without the participation of energy in various forms!

While the fact of energy is an every-day one, with the term not nearly so well known, the condition is exactly reversed as to culture, The word is generally familiar, but an agreement between any two or three educated people as to a definition will be hard to secure. There are many definitions of this term which it would seem usefulness of energeties will show itself in its ability to embrace all of the many sides of the cultural problem. All life, individual as well as social, utilize those forms of energy that it comes into contact with for its own purenergy that it comes into contact with for its own pur-
poses by suitably transforming them. The result of this transformation may be great or little, as compared with the energy expended, much as a skilled artisan may, in a given time, do tenfold the work of an unskilled one. Ostwald makes the extremely significant assertion that the measure of culture is the efficiency of transformation of raw energies to human purposes. As the teaching of the schools have robbed most of us of an untrammeled
vision, an explanation and a justification are in order:

All ancient culture was based on the existence of slaAll ancient culture was based on the existence of sla-
very. Only through it could a few acquire that leisure and the means essential to free scientific pursuits. Thi resulted in the involuntary equation of possession of slaves with high mentality, and the despising of all
technical work as fit only for slaves. But the ancients * Presidential address delivered before the Engineers' Club of * Presidential address delivered before the
Philadelphia. and published in its Proceedings. themselves disproved this original hypothesis, since among the chief furtherers of culture there wers found more and more slaves and freed men, because culture is based on work, technical as well as mental; between these two also the difference grows increasingly less.

If we can imagine ourselves back into the probable initial condition of human development, we see beforo our mental vision a being that is not superior to its surroundings by either strength, speed, invulnerability of covering, or otherwise advantageously fitted for the fight for existence; it is also not guarded against dying out by such protection as is found in a particularly simple organization or by great fecundity. A single uality differentiates this being from others, the of increanty differentiates this being from others, that of increasingly freeing itself from the influence of changing conditions of
existence by the formation of new, or the intentional retention of old, beneficial conditions. It is this quality that finally gave to this weakly and poorly fecund race the dominance of the earth. Wherein lies the essence of this advance? What is the basic principle involved? Ostwald answers his question that man learned to apply one transpurper first the native that of other men (slaves), of animals, of plants, and that of other men (slaves), of animals, of plants, and
finally the anorganic energies (wind, ground wealth, water power). The possession of energy in the sense of water power). The possession of energy in the sense of
physical energy or the generalized idea of work means the domination of the world. If, to-day, more than ever before, the ownership of mobile capital carries with it this domination, it is because capital represents the most concentrated and most readily transformable form of energy.

It is often said that man acquired the domination of the world by his reason, and that reason carries with it the concentration of great power in the individual. This is true so long as reason is directed to acquisition of energy and its purposeful employment. Chess certainly does call for the exercise of considerable reason, and a champion certainly does develop much reasoning power when playing a game with a worthy opponent. But this is not directed to the energy problem, and is, thereforc, foreign to culture; the latter would probably be greater rather than less, did nobody play chess.

When some primitive man first found that using a broken tree limb enabled him to strike an opponent, animal or man, before that opponent could close' with him, the first step was taken in the path of purposeful transformation of energy.

Purely mathematically the inclusion of the weapon (tool) did not permit the full application at the intended place of the entire muscular energy used. But the lesser application. Whereas the forefather of this inventor had to pay for each bear choked with the bare hands by wounds and days or weeks of inability to work, the cudgel wielder could kill his bear without being even scratched, and saved himself the days of nursing. He was, therefore, able in the same time and with the expenditure of the same amount of energy, to kill far more bears than his brave ancestor, who did not know how transform his muscular energy by use of the cudgel.

The same may be said of each advanee in culture; that is, either a more useful transformation of personal bodily energy, or the economic utilization of foreign energies for personal account. The first step in this second direction is undoubtedly the utilization of the man power of others, first having learned to direct and form that to one's own will. This brings before us for the first time the remarkable fact that by energy of higher grade lesser energies are dominated, even though
the absolute amount of the subjugated far exeecd that of the dominant energy. More remarkable still, all uprisings of slaves have ended in fiaseo; in other words, uprisings of slaves have ended in fiasco; in other words, have failed because these raw energies lacked organization. Only from the union of rising classes with rulin classes, where, therefore, the raw energies were organized did lasting forms result. So it was in the history of the of the French Revolution, with its consequences, in which the intelligence and the organizing abrlity of the upper classes were still needed to make permanent that freedom of the masses acquired by mere brute strength. Ostwald then develops the same thought through the Ostwald then develops the same thought through the
beginning and progress of the utilization and domination by man of the animal and plant world. The traditional reverence of the mythical discoverer of fire show that the enormous step in the regular utilization of days. But the period of the extended and systematic utilization of anorganic energy has but begun, and may be counted back over barely a century. It beg $a_{\mathfrak{n}}$ with the introduction of the steam engine with the nineteenl. entury, is now passing through a new developmen 6 made feaible scientifically by finally have to take up the problect of the utilization of solar energy that is now but poorly solved by plants solar energy that is now but poorly solved
with an efficiency of less than 1 per centum.

The older point of view-that of the adherents of the older "classic" education or "culture" - would make the advance of mankind in the technical arts, and the material ease that in turn gave time for the practice of this culture, a result of the culture. This idea is abhorrent to the strict logician, as making a result produce itself. Ostwald has clearly pointed out the logical line of development. Refer back again to the existence of a high classic culture as based on the leisure due to slavery, and then to the almost total loss and extinetion of this culture, and its renascence and far wider and more general distribution as a result of the application of mental effect to the despised handiwork and brain work of the technician and scientific worker. The old classic arts had but a hectic existence and an early death, because based much as the consumptive shows a complexion envied by much as the consumptive shows a complexion envied

The necessity for this order of development is clear. since the progressive dominance of the other energies to that of the anorganic ones demands an increasing faculty for abstract thinking, which can but be the product of a greatly advanced real culture. That others can work a we do is a thought easily grasped; but that an animal may be trained to work does not fail to astound every child-is, therefore, unexpected. That a piece of wood or coal may work was so far fetched an idea that it required thousands of years before the thought occurred to man. And the law of the conservation of energy, which man. And the law of the conservation of energy, which
first permitted a clear view of this vast field, and with first permitted a clear view of this vast field, and
that its dominance, is barely sixty-eight years old.

So far the advance of culture has been considered only in its more narrow technical sense. Is there also a connection with the social and political organization in families, races, and people, with the State and law? At first glance the question of energy would appear to have nothing to do with these matters, and this would be true were it only a question of the law of the conservation of energy. But what purpose do organization, law, state and the various other social forms of mankind surve other than the increasingly useful utilization of the available energies? What else is the law but an arrangemen which permits each individual to devote his energies to a useful purpose, without having to deflect a portion to defense from predatory neighbors?

Ostwald next follows the development of war and armies from the early mere aggregation of mon depending upon their muscular energy, to the defeat and displacement by those first using animal energy (cavalry) to their defeat in turn through the utilization of mor oncentrated forms of encrgy, as in gun-powder, and t the change from loose aggregation to the present firm aggregation into a relatively small number of powerful nations, and then draws a parallel with eapital.

Simultaneously, another form of energy concentration has developed power as "mobile capital.". The encrgy masses that are to-day collected in this power exceed by far those concentrated in armies; money is more nocesary for war than are soldiers.

As in the beginning of the organization of States, the clans were the real embodiment of concentrated energy, and the life of each State depended upon its ability to weld these elans into larger units without the former continually tending to defect, we are to-day confronted by capitalistic organizations, with individuals and small unions striving to secure the benefits to themselves. Whereas no State to-day would tolerate an individual person maintaining at his personal disposition a body of armed men, the State does tolerate the concentration of the infinitely greater might of mobile capital in the hand of the individual, making it possible for him to levy tribute on the entire world. Ostwald here points to the monopolization of petroleum by Rockefeller, to hindor which the President of the United States even does not ppear to possess adequate nower. ${ }^{1}$

The condition is about the same as toward the close of the middle ares, when the leaders of the mobile free-lane soldiery were practically the rulers. Necessarily, the newer development will have to follow a similar path, as the State must itself, in self-defense, undertake the concentration of capital and thus utilize its resultant immense energies for the best interests of its citizens. It is true that this will necessitate the disappearance of the ${ }^{2}$ This was written in 1909, before the revent settlement (?), hy 
superstitious fear of the interference of the State with private possessions, a Pandora's gift handed down to us, with a choice collection of others, from the old Roman law.

Concentration of capital in the individual has proved itself to mean the most intense possible conversion of the raw energies (mineral, etc., wealth) that the individual or individualistic group controls, into capital energy, without regard to their rational utilization in the interest of the entire community. The concentration of capital in the hands of the State, carrying with it the control of all of these raw energies, substitutes for their conversion in the selfish interest of the few their utilization in the interest of all We must not consider in the shortlimited treasures. but find our pride in satisfying our cultural needs with the least possible using up of our raw energies, and not forget the purpose of our life over its means.

Having grasped the significance of this idea of physical energy, its central relation to the extraneous, economic, and social side of human culture may be granted; but can it be applied also to art and science, these highest blossoms of our culture? The answer does not seem doubtful. Quite aside from this much-debated question of psychic energy, it is clear that art and science must be of psychic energy, it is clear that art and science must be
carried on. To carry them on a bodily organization is necessary, the productivity of which depends upon many circumstances, among which a happy increase of productive ability is of chief importance. But this is possible only if the mental apparatus disposes of sufficient free energy. As an old man, Goethe complained much of the diminishing productivity of his later years; it was clear dinis A clear his work in the early morning hours, having found that his work in the early morning hours, having found that
the lessened energy at his disposal in old age was not sufficient to overcome the distractions of the later day and permit other work. The highest work of genius, all other work, reduces itself to a transformation of energy. It is merely a form of energy of great rarity an corresponding value into which genius converts the lowe forms. Its high value again resides in the fact that influences other men to the better conversion of their energy. The chemist knows phenomena of this characte as "catalysis": an action that ordinarily takes place slowly, even unnoticeably, is incomparably quickened by the presence of a substance that finally comes out of the reaction itself unchanged and undiminished. That the action of a work of art on a receptive mind: it doe not increase the absolute amount of the existing energies, because energy cannot be created; but it does accelerat the rate conversion of the existing energies, and instead of purposeless dispersion, promotes their working together in harmony toward a valuable end. In th catalytic effect of art Ostwald finds the social value an significance of art; it is not only a purpose, but a means to an immensely valuable end.

The social economic value of science is even plainer by far. There is no such thing as science for its own sake (note the significance from a past master of science)that would be mere play-no, science exists for huma ends. Such phrases as idealism and utilitarianism ar handy, not to disprove this statement, but merely to decry it for those without judgment.

Whoever follows science for narrow personal ends, to him she is but a milch cow. The sound-thinking and feeling man will enthusiastically follow science whenever he recognizes and feels its social value, be his branch for him to lighten human burdens and increase human joys-in a word: to better mankind's utilization of its ever there would seem to be a science so academic that it could be followed only for its own sake, this must be it. But a moment's thought will show that the development of logic may decrease the sum of human errors and so make clear the practical value of this science.

One may ask one's self whether any great amount of human discomfort and useless work may be saved by human endeavor. The true scientist will answer "Y es," and in that answer find the enthusiasm and persistence needed for creative work and real advancement of science But he who has not this perspective, who does not find this practical viewpoint, will but hunt a "job."

Idealism is not a lack of purpose, as those who follow purposeless things would have us believe; on the contrary, it is the most intense knowledge of purpose; but the purpose must be set high enough to merit the name of idealism. And all these high purposes may again be viewed as the delivery of mankind of its burden and the enhancement of its joys. But relief from burden is a diminishing of energy used for a given purpose, therefor improvement in efficiency, while increase of enjoymen means increased activity of the nobler energies resulting from a freeing of a greater portion of the total energy for that purpose-in the end the same thing. We, therefore, inevitably arrive again and again at the same viowpoint, and must be convinced that we have found a scale for the measurement of every human endeavor.

The law of the conservation of energy, also, was first doubtfully accepted, even denied, but to-day we know that there is no physical phenomenon which may not be brought into a definite equation on the basis of this fundamental law.

Ostwald closes with the enunciation of a new law, deduced through a similar development of ideas that:

The me sure of culture is the efficiency of the transform

tion of raw energies to humanly valuable purposes.

\title{
The Chemistry of Sewage Disposal
}

\author{
Chemical Action the Basis of Every Successful Method
}

\section{By Georǵe G. Nasmith}

IT is now the accepted theory that bacteria and other forms of life are invariably necessary in order to obtain fixed results from any method of sewage disposal. It is recognized that these work under more or less definite, fixed conditions, and demand certain treatment; that they can be governed to perform their functions efficiently, and, finally, in the performance of their work that they depend on a free supply of oxygen to completely they depend on a free supply of oxygen to completely
oxidize the organic matter and create a non-putrescible oxidize

It came to be recognized that one could obtain all sorts of hydrolytic decomposition in septic tanks, or under anaerobic conditions, with productions of proteoses, peptones, amino acids, nitrites, hydrogen sulphide, methane and hydrogen; that these decomposition products were still for the most part putrescible, and sometimes more difficult to handle than the raw material from which they were derived, and that, after all, the complete end products of any method of decomposition complete end products of any method of decomposition
depended on the fact that oxidization of carbon gave carbonic acid; of nitrogen gave nitric acid; of sulphur gave sulphuric acid, and of hydrogen, gave water. These are the final products obtained in any completely oxidized sewage. Sewage dispat -Oxygen = Inorganic stated:
+Humus.

As the object of every method of sewage disposal is to create a non-putrescible effluent, and more recently a non-pathogenic effluent, the anaerobic methods, such as that of the septic tank, have failed because of this one fact, that the end products of anaerobic action are still putrescible, and must be further treated.

The real biological oxidation methods may be grouped together, since the action taking place in them all is practically the same. These are (1) Intermittent sand filtration, which really is an improvement on the older methoe of sand filtration; (2) Contact beds-single, double, or triple, and (3) Trickling filters.

In all methods of sewage disposal it is deemed advis able as a preliminary to remove as much of the suspended material as possible, by means of the various forms of sedimentation tanks.

Now, if the materia! is sterilized in any of these methods, no action, or only a very slight one, takes place. If the sewage is treated with disinfectants, the same thing occurs; but if these various types of beds are given repeated doses of sewage, the organic matter is graduall converted into inorganic salts, and the filter become converted into inorganic salts, and the filter becomes
matured. At the same time it is found that the sand matured. At the same time it is found that the sand
granules, or stone, slag, or other material, becomes coated with a gelatinous layer containing bacteria, organic material and iron. As the gelatinous film becomes thicker, the purifying action is improved.

In such a matured, intermittent sand filter, Dunba - Reproduced from the Enoineering Magazine. found that if a gallon of a solution of albumen was poured on to the top of the filter, a gallon of water, less the
albumen, flowed out at the bottom. That this was the same water he proved by adding readily detected chemicals, such as potassium iodide or fluorescein to the original solution. When repeated at intervals he found that the sulphuric acid in the effluent corresponded almost exactly to the sulphur in the albumen, while only part of the nitrogen appeared as nitrate, the rest of the nitrogen disappearing as free nitrogen or remaining locked up in the humus, which was formed in small quantities. A portion of the carbon also disappeared as carbonic acid while the balance was retained in the humus. The remarkable fact, therefore, became apparent, that a solution of albumen or sewage may leave an intermittent sand filter thoroughly purified in ten minutes. In other words, the organic material in the sewage became absorbed by the gelatinous material covering the granules in the filter. It is known from experience that micro-organisms cannot decompose such material in a few minutes.

By excluding air from the filter, it was found that such purification ceased to take place. By sterilization of the bed, or when disinfectants were added to the sewage, purification also ceased. The principle became fixed that bacteria in presence of air were essential for purification.

It was then demonstrated that in a matured contact bed, if quantities of distilled water were added at intervals, there would be considerable quantities of nitrates found in the effluent, and carbonic acid would continue to be given off and found in the air of the filter. The conclusion was therefore very obvious. The organic matter was first absorbed by the gelatinous film, and during the periods of rest while in contact with the air, this was decomposed with the aid of organisms, during which process oxygen was used up, and fresh oxygen drawn into the filter. This latter fact has been proved with the aid of capillary tubes inserted into the beds and connected with manometers. If a contact bed is and connected with manometers. If a contact bed is
filled with sewage, and air is blown in at the bottom, the free, unabsorbed oxygen is unable to carry out the necessary oxidizing action, and the sewage is not rendered non-putrescible. The oxygen thus absorbed during intervals of rest seems to be condensed on the surface of the gelatinous film, into some more active form, possibly as ozone, by the high pressure which is known to exist in such gelatinous films.

In the trickling filter, the principle of oxidation has been carried to its logical conclusion. In such beds, the sewage is continuously sprayed over the surface by one of the innumerable devices for the purpose. The bed itself is composed of some hard material, preferably of that the filling readily weather, and is so arranged top and larger toward the bottom, so that humus-like substances formed may be readily washed away. Sewages which could not be treated satisfactorily in contact beds were handled satisfactorily by simply trenching the surface of the bed, placing a layer of sand along the bottom of the trench, and allowing the sewage to flow along these trenches, the raised parts allowing free access of oxygen. The contact beds were thus converted into trickling filters, and the results were eminently satisfactory.

The septic tank, which is wrong in principle, except in so far it mav prove useful as a liquefying agent, is already doomed as an integral essential to any method of sewage disposal.

The contact bed, which is on a right principle, wrongly carried out, will also probably soon disappear. The intermittent sand filtration method, which is satisfactory in principle, is very expensive to construct and maintain for a given unit of sewage treated.

Based on purely theoretical principles, and with the experience already gained, in point of economy and efficiency, there is no doubt but that the trickling filter has come to stay and is bound to displace all present forms. The sedimentation of the humus-like material from trickling filter is readily accomplished, and should constitute part of the system in order to obtain a clear effluent suitable for disinfection with chlorine

The disinfection of raw sewage by chlorine may prove a valuable compromise in some rare instances when other methods of treatment are not possible, but is said to be not working out as well as was expected. It should prove of great value in rendering a clear effluent from biological sewage disposal svstems absolutely safe.

Manganese in Steel Production.-Ferro-manganese is liest added to steel in the heated state, as if it is put in cold it causes a cooling down of the metal and more ferro-manganese is needed than theory requires. Besides the misture lacks in lomogeneity. It is thus desirable to melt the metal, lint much of it is lost by rolatilizing in this case. In Germany a very good method is now used, the ferro-manganese being melted in a Keller electric furnace at the Burnbach steel works. The cost of melting the 4,000 tons of ferroinanganese needed for treating 800,000 tons of steel (an electric meiting furnace being used), but much economy is secured by the fact that there is scarcely any loss of the metal, which is now employed in the melted state, so that less of it is needed. Supposing that the amount is lessened by two pounds per ton, this gives a saving for 800,000 tons of steel of 800 tons of ferro-manganese, which valued at $\$ 40$ a ton figures out to $\$ 32,000$. 